\title{
EDITORIAL
}

\section{LA EDUCACIÓN OLÍMPICA: UN RETO PARA LA UNIVERSIDAD COLOMBIANA}

\author{
Germán Anzola Montero \\ Rector
}

En el marco de la 11 Sesión Conjunta Internacional para Presidentes o Directores de Academias Olímpicas Nacionales, evento que se llevó a cabo en Olimpia, Grecia, en mayo de 2012, tuve la oportunidad, como Vicepresidente de la Academia Olímpica Colombiana y como Rector de la Universidad de Ciencias Aplicadas y Ambientales U.D.C.A, de expresar y dar a conocer criterios y juicios sobre la relevancia que tienen las Academias Olímpicas y su articulación con las Universidades, en el empeño de implementar acciones educativas y culturales alrededor del olimpismo y actividades relacionadas con el ejercicio y el deporte, a favor de la niñez y de la juventud.

Esta intervención tuvo como preámbulo, una breve síntesis sobre la influencia de Pierre de Fredy, Barón de Coubertin, desde que lideró la creación del Comité Olímpico Internacional, en la Universidad de Sorbona, en París, el 23 de junio de 1894, un hito en la historia del deporte mundial, particularmente, porque su génesis fue en el seno de una Universidad. Desde ese momento, este ilustre pedagogo y pensador francés, como buen visionario, encontró en estos paraninfos un excelente escenario para discutir y para difundir la filosofía del Olimpismo, como un medio privilegiado para la formación de la juventud.

Por lo anterior y fieles a los ideales de Coubertin, la Academia Olímpica Colombiana ha asumido el reto de vincular a las Instituciones de Educación Superior del país, comprometiéndolas con el propósito de educar a los jóvenes, a través de experiencias pedagógicas para su formación integral, es decir, para la Universidad colombiana resulta crucial, en los procesos de enseñanza de sus estudiantes, abordar el tema del olimpismo y del deporte, desde una perspectiva filosófica e histórica. Adicionalmente, la Universidad deberá divulgar el olimpismo, como un estado de equilibro, entre el cuerpo y el alma, entre el espíritu y la materia, entendiendo que el olimpismo va más allá del deporte, puesto que es inseparable de la educación y ha encontrado en la difusión del juego limpio, su mejor sendero y ello, es hoy, una realidad.
Para avanzar en este proceso de formación, señalé que habíamos partido de la siguiente premisa: que el olimpismo, en un alto porcentaje, es desconocido en su evolución sociohistórica y cultural y, que además, lo han aprovechado y disfrutado quienes están inmersos en el mundo de la actividad física y en las organizaciones ad latere, que conforman este círculo y enfaticé que era aun más ignorado por una gran población, principalmente, por las nuevas generaciones. No es preciso olvidar que el deporte tiene amplias y profundas justificaciones: en lo social, como fenómeno de masas; en lo humano, por su invaluable aporte al desarrollo integral del individuo; en lo político, como medio de integración de comunidades, modelo de organización y gobernabilidad; en lo económico, por la generación de empleo y movilización de recursos; en lo económico, por su formación en valores; en lo ambiental, por hacer del hombre un individuo más resistente a las condiciones del medio; en la salud, por la prevención de enfermedades; en lo laboral, por aumentar la capacidad de trabajo del hombre y en lo estético, por la expresión de belleza, armonía y verdad. Todo esto constituye la base para la formación de una auténtica cultura deportiva.

Como modelo de esta alianza expuse la primera experiencia exitosa de la Academia Olímpica Colombiana en el ofrecimiento de la Cátedra de Estudios Olímpicos y del Deporte, la cual, se ha oficializado en varias universidades y cuyo propósito es estimular la formación de una cultura de paz, por medio de los estudios del olimpismo y del deporte. Representa un oportuno medio para fomentar valores, con el fin de asegurar la convivencia pacífica, la vigencia del orden justo, el respeto de los derechos humanos y el medio ambiente, como preceptos fundamentales de la Constitución Política Nacional.

Los rectores de las Universidades que venimos liderando esta iniciativa tenemos la plena convicción que el deporte y la filosofía olímpica refleja un medio que favorece la construcción de una cultura nacional. En este sentido, la Universidad, como generadora de conocimiento, deberá estar comprometida con estos ideales, los que permiten el 
diálogo racional con la sociedad. Así mismo, en Colombia estamos luchando incesantemente por alcanzar la paz, por tal motivo, todas estas acciones coadyuvan para que los niños y los jóvenes colombianos puedan convivir en armonía, en oposición al arraigado individualismos que impera en las comunidades deportivas y educativas, es decir, una correcta formación, cuyo eje es la participación, mas no la competición.

Indiqué, también, que la Academia Olímpica Colombiana, desde 1993, con el apoyo de algunas Instituciones de Educación Superior, entre ellas, la Universidad de Ciencias Aplicadas y Ambientales U.D.C.A, ha liderado otra iniciativa educativa y cultural, de la cual, ya se han visto sus primeros resultados. Hago referencia a las Tertulias Olímpicas, espacios que se han convertido en discusión, en análisis y en difusión cultural, en la esfera nacional e internacional.
Las Tertulias, a pesar de caracterizarse como ambiente informal y que no hace parte de un proceso educativo sistemático, se ha convertido en un espacio de reflexión, favoreciendo la construcción de una cultura olímpica. Es así, como a través de la historia, la sociología, la filosofía, la filatelia, la antropología, la política, la ética, la religión, la administración y la educación física, entre otras disciplinas, se ha abordado el movimiento olímpico, no como una organización sino como una forma de vida.

Concluí esta presentación, manifestando que un sector de la Universidad colombiana ha creído que, apostarle al movimiento olímpico desde un trabajo sinérgico y armónico con la Academia Olímpica, permitirá avanzar y profundizar en él, como una filosofía que hay que preservar y cimentar en nuestros niños y jóvenes, en quienes debemos forjar valores ciudadanos, para que favorezcan la sana y la solidaria convivencia entre las Naciones. 